\title{
Retraction Note to: Carbon Dots as Artificial Peroxidases for Analytical Applications
}

\author{
Shih-Chun Wei ${ }^{1}$ Yang-Wei Lin ${ }^{2} \cdot$ Huan-Tsung Chang ${ }^{1,3}$ (1)
}

Published online: 23 March 2020

(c) The Nonferrous Metals Society of China 2020

\section{Retraction Note to: \\ Journal of Analysis and Testing (2019) 3:191-205 \\ https://doi.org/10.1007/s41664-019-00107-x}

The publisher has retracted this article [1] due to an operational error during the publication process. The authors agree with this retraction.

\section{Reference}

1. Wei S, Lin Y, Chang H. Carbon dots as artificial peroxidases for analytical applications. J Anal Test. 2019;3:191-205. https://doi. org/10.1007/s41664-019-00107-x.

The original article can be found online at https://doi.org/10.1007/ s41664-019-00107-x.

Yang-Wei Lin

linywjerry@cc.ncue.edu.tw

$\bowtie$ Huan-Tsung Chang

changht@ntu.edu.tw

1 Department of Chemistry, National Taiwan University, Taipei 10617, Taiwan

2 Department of Chemistry, National Changhua University of Education, Changhua 50017, Taiwan

3 Department of Chemistry, Chung Yuan Christian University, Taoyuan City 32023 , Taiwan 